\title{
EDUCAÇÃO A DISTÂNCIA
}

\section{Colocar as novas tecnologias da comunicação a serviço da educação ajuda a diminuir as distâncias sociais e pode propiciar, a cada vez mais pessoas, 0 direito ao saber}

Todo homem deve ser capaz de viver e agir no espaço do saber e as tecnologias utilizadas pela humanidade sempre tiveram um papel fundamental na organização das sociedades humanas. A palavra, o desenho, os gestos, a escrita são tecnologias que modificaram e contribuíram para a evolução das sociedades.

Estamos vivendo a terceira revolução industrial, a revolução da inteligência, estruturada numa economia cujos lastros financeiros, por sua vez, se alicerçam numa nova moeda globalizante - a informação. As decisões tomadas no cotidiano das pessoas são balizadas pelo acesso que se tem aos meios intermediadores da informação. Das bolsas de valores às compras no supermercado, estão-se utilizando as redes de informação disponíveis.

Vivemos em uma sociedade virtual, na qual a imagem e o som têm um papel preponderante na formação informal do homem moderno. A geração que está com 18 anos hoje cresceu diante da televisão, as fitas de vídeo se popularizaram, o videogame já é tão comum no imaginário infantil quanto os contos de fada.

\section{O AUTOR}

Luís Lindolfo Nogueira

Técnico em Educação a Distância, no Estado de São Paulo.
Todos estes canais de informação e de entretenimento são pesquisados atualmente e, como mostram alguns resultados observados por pesquisadores na França, a criança, embora leia o manual de instruções para aprender a linguagem videográfica e o manuseio dos jogos, descobre as regras analisando espontaneamente os casos particulares com que se depara, exatamente como faz um pesquisador científico ao buscar a regra geral de experiências particulares. Os trabalhos de Michael Serres e Pierre Lèvy ${ }^{1}$ afirmam que há modos de conhecimento inéditos que emergem do uso de novas tecnologias. Lèvy lembra que elas fazem parte do cotidiano das sociedades contemporâneas e portanto são intrínsecas ao mundo simbólico e ao imaginário dos homens.

\section{MÍDIAS EDUCATIVAS}

Deve-se compreender que não há necessidade de o indivíduo estar literalmente diante de um computador para ser usuário de novas tecnologias. Ao assistir a um programa de televisão, ouvir um programa de rádio, falar ao telefone, ler um livro, andar de automóvel, o homem usufrui das mais avançadas tecnologias. Isto sem falar de uma cópia de xerox ou de um saque bancário.

As novas tecnologias aglutinam a escrita, a imagem e o som sem descartá-las ou compartimentalizá-las. São conexões inter-

1. LÈVY, Pierre. As tecnologias da inteligência: o futuro do pensamento na era da informática. Rio de Janeiro: Editora 34 , 
relacionadas, que possibilitam outras abordagens e novas relações.

Conforme Pierre Lèvy, "os produtos da técnica moderna, longe de adequarem-se apenas a um uso instrumental e calculável, são importantes fontes de imaginário, entidades que participam plenamente das instituições de mundos percebidos".

É, portanto, como diz Authier ${ }^{2}$, lamentável que a escola não leve em conta as ferramentas pedagógicas que possam proporcionar prazer no processo de construção do conhecimento.

$\mathrm{O}$ desenvolvimento da Educação a Distância no mundo está intrinsecamente ligado ao desenvolvimento tecnológico das sociedades, tornando inevitável sua associação aos avanços da informática e aos meios de comunicação de massa.

Pensar a escola sem as novas tecnologias é condená-la a permanecer na Idade Média, é lutar contra o presente e o futuro das próximas gerações. Nesse sentido, é preciso aprofundarmos o debate sobre o seu uso na Educação.

Num primeiro momento encontramos, como diz Umberto $\mathrm{Eco}^{3}$, os integrados aqueles que vêem as novas tecnologias de forma acrítica - e os apocalípticos - que as supõem como modismos.

Superada esta fase, sensibilizamo-nos a respeito do seu aproveitamento e da ajuda que elas nos proporcionam, mas quando retornamos para a sala de aula somos convencidos, mais uma vez, da impossibilidade do uso de novas tecnologias na realidade que nos cerca.

Para que possamos usufruir dos seus benefícios, precisamos entender como se processa a comunicação na escola. Podemos co- meçar pela observação e análise do cotidiano da sala de aula. Estamos falando basicamente da atividade de docência e nela poderíamos abordar diversos fatores que interferem na relação professor/aluno e a construção do conhecimento, mas aqui nos compete enfatizar a relação comunicacional entre professor/aluno no cotidiano escolar. Conhecemos a dura realidade do dia-a-dia da sala de aula. Quer nas escolas públicas, quer nas privadas o professor tem à sua disposição parcos recursos.

O trabalho docente sempre esteve baseado no desempenho do professor, cujo canal de comunicação permanece, até os dias de hoje, centrado na oralidade e na escrita, tendo como tecnologia disponível o quadro-de-giz. Quando muito, ele conta com o mimeógrafo e o livro didático. As escolas mais abastadas possuem máquina de xerox e uma sala equipada com televisor e videocassete.

As poucas unidades que oferecem computadores aos alunos já se consideram no Século XXI.

Quando optamos por investir em novas tecnologias na Educação não significa que devemos decorar a escola com as inovações da modernidade, pois o que realmente importa é o uso que se faz delas - e esta é a principal dificuldade dos educadores.

Além disso, é preciso mudar o foco de análise. Quando se pensa em novas tecnologias, não é o vídeo ou o programa de computador que deve vir em primeiro lugar e sim o projeto que se busca desenvolver, pois este novo ambiente cognitivo traduzirá a rede de relações humanas que se quer instituir. 
É nessas relações que se estrutura a comunicação entre professor/aluno, realizada através das mídias educativas - o quadro-de-giz, o livro didático, o cartaz, o slide, a fita de vídeo etc. Estas são as ferramentas com que contamos para executar um plano de aula; no entanto, até mesmo as mídias mais comuns, como o quadro-de-giz e o livro didático, são utilizadas muitas vezes de forma inadequada, tanto pela escola pública como pela privada.

Este é o ponto de partida para aprofundarmos o debate sobre o uso das mídias educativas.

Também devemos estar atentos para a dimensão política, social, econômica, educacional e cultural sobre o uso das mídias. Selecionar um livro didático, um vídeo, um recorte de jornal, uma canção, um poema requer um pouco mais de cuidado em relação à função que este instrumento deverá cumprir dentro do plano de aula. A exibição de um vídeo, ou a leitura de um ponto, ou a escolha de um livro pode tanto contribuir para a ampliação e aprofundamento de um tema como estar totalmente desconectada do objetivo proposto, ou pior, ser mal utilizada, estimulando preconceito em relação aos meios, os quais são essenciais para que o homem possa usufruir os bens culturais da humanidade.

Um primeiro passo para a escolha adequada das mídias educativas é planejar cuidadosamente a aula, levando em consideração a cultura, as relações sociais e o poder econômico da clientela envolvida.

Como alerta Authier, é preciso ter consciência que o ato da escolha tem uma dimensão política. Para a produção destas mídias educativas nota-se que há o envolvimento de vários setores de nossa sociedade, principalmente dos setores econômico e tecnológico. A tecnologia, a economia e a sociedade estabelecem uma relação ética e po- lítica sobre o uso das novas tecnologias e é nesta dimensão que podemos atuar.

Cada parte da sociedade que deixar de usar e influenciar os meios tecnológicos estará sendo submetida às regras estabelecidas por outros e, portanto, perdendo a sua liberdade. Somente com o domínio sobre o uso das novas tecnologias é que podemos reverter o processo, pois a tecnologia e a economia buscam atender aos interesses dos usuários, neste caso, a escola pública.

A Educação a Distância também é uma modalidade educativa que, como o próprio nome sugere, possibilita a supressão de distâncias geográficas, econômicas, sociais, culturais e até mesmo psicológicas.

\section{ELIMINAR DISTÂNCIAS}

A distância geográfica não se traduz em uma quantidade de quilômetros que separam seus usuários. Além do alcance espacial, ela também auxilia na supressão do tempo. Essa modalidade de ensino permitenos trabalhar com uma sala de aula virtual, sem limitações físicas e cronológicas e que possibilite ao aluno organizar o seu tempo de estudo, atendendo assim não só o cidadão que, embora resida vizinho à escola não tenha codições de freqüentá-la diariamente, como também aquele que se encontre a milhas de distância.

Outro ponto importante é a questão da qualidade dos cursos oferecidos. Todos os conteúdos, desenvolvidos minuciosamente pelos melhores especialistas, são testados previamente. Posteriormente, nos telepostos, esses contéudos são aprofundados, privilegiando-se a troca de experiências e a resolução de dúvidas. 
Estudos realizados nesta área demonstram que não basta dar acesso ao conhecimento por meio da Educação a Distância se o indivíduo se deparar com uma barreira psicológica entre o seu conhecimento e aquele colocado à sua disposição. Isso porque, como diz Serres, tal distanciamento é uma forma de exclusão social, que leva o indivíduo a menosprezar o conhecimento já adquirido e a se supor totalmente ignorante diante de novos conhecimentos, principalmente quando esse conhecimento se encontra nos círculos acadêmicos.

Serres também afirma que há uma concepção sobre o saber em que seus possuidores se fecham numa fortaleza e o conhecimento se torna uma forma de poder, permitindo o controle de quem está fora desse espaço, intensificando o mito da linearidade na construção do conhecimento.

Só o saber nos dá a possibilidade de agir e interagir na sociedade moderna e o distanciamento dos saberes condena $o$ indivíduo ao isolamento, à discriminação $e$ à exclusão de sua cidadania.

Vários segmentos da sociedade estão evoluindo através das novas tecnologias da comunicação e a Educação deve ser parceira nesta construção.

Diante de um novo saber é preciso reconhecer o que lhe é comum, buscar uma entrada para esse contexto e descobrir o seu sentido mais complexo. $\mathrm{O}$ uso de qualquer mídia educativa deve respeitar as diversidades de aproximação, levando em consideração que os objetos não podem ser estudados independentemente das pessoas. É preciso evitar fechar o sistema de ensino numa lógica racionalista, com uma só entrada, um só caminho, uma só saída.
Além disso, há a velocidade da modernidade, que podemos contextualizar como o "avanço do conhecimento científico e sua incorporação no cotidiano através da técnica; incorporação do conhecimento científico e técnico nas relações de trabalho; universalização das comunicações e do processamento das informações, mundializando as relações culturais e os valores; mundialização das relações produtivas da economia; surgimento do Estado Moderno, caracterizado pela participação de todos na sua administração; afirmação da cidadania como direito universal; declaração dos direitos políticos como direito subjetivo"4.

\section{DIMENSÃO DO CULTURAL}

Hoje, o conhecimento torna-se um dos paradigmas das novas teorias endógenas de crescimento. As pesquisas lideradas pelo professor Paul Romer, da Universidade da Califórnia (campus de Berkeley), singularizam o conhecimento e suas consequiências econômicas como um fator central propulsor do processo de conhecimento.

Nesta nova ordem mundial, o modelo de desenvolvimento econômico está sendo repensado, amparado por um conceito jamais abordado em escala mundial: a cultura. Nas portas do terceiro milênio há uma iniciativa mundial, de crescimento sustentável sobre a base do desenvolvimento cultural.

Uma das entradas para ampliar o conhecimento humano é desenvolver programas de Educação a Distância que levem em consideração as dimensões culturais do público alvo. Toda pessoa constrói seu conhe- 
cimento a partir de sua bagagem cultural, intelectual, sensorial, que lhe permite circular no seu espaço social.

Como diz Morin, "a Cultura reúne em si um duplo capital: por um lado, um capital técnico e cognitivo - de saberes e de conhecimentos - que podem ser transmitidos, em princípio, a toda e qualquer sociedade e, por outro lado, um capital específico que constitui as características de sua identidade original e alimenta uma comunidade singular por referência a seus antepassados, seus mortos, suas tradições" 5 .

O conhecimento que está no cotidiano se forma, conecta-se com outros saberes, ampliando cada vez mais seu espaço de circulação no mundo. A forma de abordagem de determinado campo do conhecimento deve levar em conta as representações sociais dos indivíduos que buscam o conhecimento. As mídias educativas no campo da Educação a Distância, ou mesmo no ensino presencial, devem auxiliar o processo de ensino-aprendizagem tendo como ponto de partida a cultura, o saber que o indivíduo detém e que permitirá a ele efetivamente alcançar um novo saber.

Ainda conforme Morin, "é preciso considerar que a cultura, como sistema generativo, constitui um quase código cultural, ou seja, uma espécie de equivalente sociológico daquilo que o código genético é para os seres vivos. O 'código cultural' mantém a integridade e a identidade do sistema social, assegura sua autoperpetuação ou sua produção invariante, protegendo-o da incerteza, da eventualidade, da confusão, da desordem".
Esse código cultural organiza as relações das incessantes transformações ocorridas na vida social, compreendendo aqui o cotidiano da vida escolar.

Um segundo fator refere-se à inteligência humana, entendida, conforme Gardner, como a "capacidade de resolver problemas ou de criar produtos que sejam valorizados dentro de um ou mais cenários culturais"6. A ciência está pautada no desenvolvimento biológico e psicológico do homem. Ao ampliar este campo, através dos estudos de Gardner, faz-se necessário incluir um conjunto mais amplo e universal das competências intelectuais, que vai além das habilidades lógico-matemática e lingüística. A aprendizagem deve levar em consideração a inteligência espacial, corporal, musical, intra e interpessoal:

* Inteligência Lingüística: revela uma sensibilidade ao significado das palavras; à ordenação das palavras (capacidade de utilizar corretamente a gramática ou de violá-la); sensibilidade à sonoridade da língua; sensibilidade às diferentes funções da linguagem.

* Inteligência Lógico-Matemática: forma de pensamento que se realiza através da confrontação com os objetos do mundo; a capacidade de estabelecer relações de quantidade, ordenação e reordenação.

* Inteligência Espacial: capacidade de reconhecer componentes inatos de um mesmo elemento; de reconhecer ou de operar transformações e modificações a partir de um elemento inicial; de recriar mentalmente aspectos de uma experiência visual, mesmo na ausência de estímulos físicos relevantes; sensibilidade às várias linhas de 
força que se aplicam à imagem como tensão, balanço, composição; capacidade de discernir a similaridade de procedimentos em diferentes áreas do conhecimento.

* Inteligência Corporal: caracterizase pela habilidade de usar o corpo de formas diferenciadas para propósitos expressivos (mímicos, dançarinos, atores, esportistas); de trabalhar habilmente com objetos, tanto os que envolvem movimentos motores finos de mãos e dedos quanto os que exploram movimentos grossos de corpo.

* Inteligência Musical (sonora): capacidade de reconhecer e operar os elementos principais da música: ritmo, melodia e timbre.

* Inteligência Intrapessoal: capacidade de compreender o desenvolvimento dos aspectos internos da pessoa; domínio das afeições e emoções, capacidade de fazer discriminações desses sentimentos de modo a facilitar o entendimento do próprio comportamento.

* Inteligência Interpessoal: capacidade de perceber e fazer distinções entre outros indivíduos, entre seus temperamentos, humores, motivações e intenções.

A Educação a Distância, alicerçada à pedagogia progressista, é multilíngüe. Se- gundo Cloutier, "ela é polissintética porque, como todas as línguas aglutinantes, incorpora várias linguagens, de tal sorte que não se possa separar os diversos elementos individuais que adquirem todo seu significado nesta incorporação. Ela é sincrética e forma um conjunto que é percebido globalmente, dando acesso às três dimensões espaciais e à dimensão temporal. A comunicação multimídia necessita da imbricação de diversas linguagens, jogando com a complementaridade de cada uma delas"7.

Assim, a Educação a Distância e a Presencial estão constantemente encontrando-se em vários momentos; porém, é importante ressaltar que a Educação a Distância não pode ser vista como substituta ou concorrente da Educação Presencial.

Cada modalidade possui suas especificidades, destinadas a atender às necessidades e demandas distintas das sociedades. A Educação, com o apoio das novas tecnologias, vem unindo essas duas modalidades e prevendo que tanto o conceito de presencial quanto o de distância serão virtuais quando todas as distâncias forem vencidas. 